\title{
Difficult to Advance
}

National Cancer Institute

\section{Source}

National Cancer Institute. Difficult to Advance. NCI Thesaurus. Code C63235.

Problem associated with difficulty moving the device to an intended location (e.g. difficulty in advancing guide wire). 